\title{
Los Pueblos Mágicos y la relevancia de la educación cultural de sus habitantes para fomentar el turismo y el desarrollo local
}

\section{The Pueblos Mágicos (Magic Villages) and the relevance of cultural education in its population, in order to promote tourism and local development}

Rosalba Bolaños Ortega; Verónica Lizardi Rojo²;

Norma Angélica Roldán Oropeza ${ }^{3}$

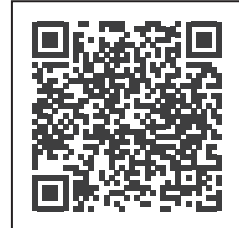

\section{Palabras clave:}

ambiente educacional; crecimiento y desarrollo; economía; nacionalismo cultural; turismo cultural.

Artículo de reflexión

Fecha de recepción: 24 de marzo de 2021

Fecha de aprobación: 21 de septiembre de 2021

Fecha de publicación: 25 de octubre de 2021

Esta publicación se encuentra bajo licencia:

Creative Commons ReconocimientoNoComercial-SinObraDerivada 4.0 Internacional

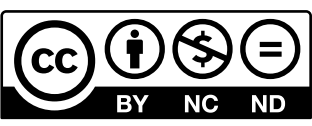

\section{Resumen}

Problemática: el turismo es clave para la economía nacional, prueba de ello es la iniciativa "Pueblos Mágicos". Para poder analizarla y hacer propuestas de mejora, se necesita un estudio a nivel país y otro de carácter particular. Objetivo: conocer la iniciativa de la marca "Pueblos Mágicos", su evolución y los diferentes proyectos generados en torno a ella. Materiales y métodos: a partir de una investigación de tipo etnográfico, es factible hacer una reflexión interpretativa de la marca, considerando que la información se consigue en documentos virtuales que emite el gobierno federal a través de diferentes entidades, especialmente la Secretaría de Turismo (SECTUR). Resultados: México tiene localidades con diversidad cultural atractiva. Es importante darlas a conocer nacional e internacionalmente para lograr un crecimiento continuo de "Pueblos Mágicos" y que cada vez más estados sean reconocidos. Discusión:

1 Licenciada en Diseño Publicitario (UVP). Universidad Tecnológica de Puebla, México.rosalba.bolanos@utpuebla.edu.mx, ORCID: https://orcid.org/00000003-1952-443X

2 Maestra en Sistemas Computacionales (UPAEP). Licenciada en Diseño Gráfico (UNAM). Universidad Tecnológica de Puebla, México. veronica_lizardi@ utpuebla.edu.mx, ORCID: https://orcid.org/0000-0002-9049-2090

3 Maestra en Sistemas Computacionales (UPAEP). Maestra en Educación (UNID). Licenciada en Ciencias de la Computación (BUAP). Universidad Tecnológica de Puebla, México.norma.roldan@utpuebla.edu.mx, ORCID: https:// orcid.org/0000-0002-8125-9617 


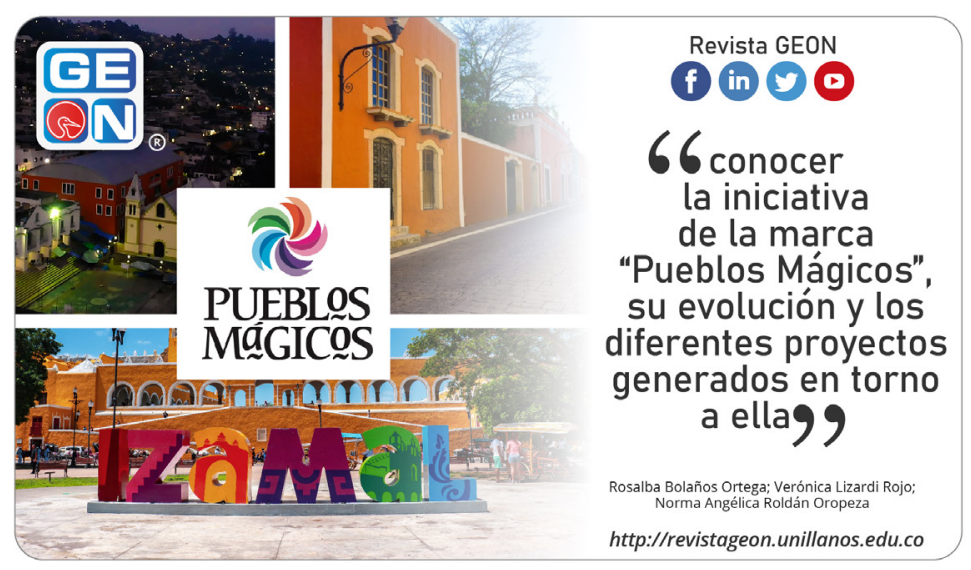

desde su inicio, el proyecto antes mencionado ha sufrido modificaciones, sobre todo en la asignación presupuestal, debidas a los cambios de administración; sin embargo, es necesario hacer una planeación integral de inversión, teniendo en cuenta el equilibrio ecológico y el crecimiento económico de los locatarios para alcanzar un desarrollo sostenible y dar a conocer los aspectos relevantes que los órganos acreditadores consideran para otorgar el nombramiento de "Pueblo Mágico". Conclusiones: el presente artículo, brinda la oportunidad de mostrar las ventajas y desventajas de la marca Pueblos Mágicos a nivel Latinoamérica. Así mismo, coadyuva a que otras naciones puedan aplicar proyectos similares para que sus poblaciones sean beneficiadas y reconocidas recordando que "La cultura es lo único que puede salvar a un pueblo [...] permite ver la miseria y combatirla, permite ver lo que hay que cambiar y lo que se debe dejar" (Periódico de Asambleas, 2017). Contribución/originalidad: las opiniones referenciadas en el presente artículo están basadas en la compilación de la información de las principales secretarías de gobierno involucradas en este proyecto. Es por ello por lo que la finalidad de esta investigación es dar a conocer la marca Pueblos Mágicos a nivel internacional, especialmente en Latinoamérica, que por su historia, arquitectura y cultura puede aplicar a proyectos similares.

V., \& Roldán Oropeza, N. A. (2021). Los Pueblos Mágicos y la relevancia de la educación cultural de sus habitantes para fomentar el turismo y el desarrollo local. Revista GEON (Gestión, Organizaciones Y Negocios), 8(2), e-442. https://doi. org/10.22579/23463910.442

Palabras clave: ambiente educacional; crecimiento y desarrollo; economía; nacionalismo cultural; turismo cultural. 
Códigos JEL: Z3 Economía turística; JEL Z Otros temas especiales

\section{Abstract}

Status: Tourism is key to the national economy. That is the reason why "Magic Villages" (Pueblos Mágicos) initiative was introduced. In order to analyze and improve this initiative, a study is needed, at a national level and another one in a particular level. Objective: To know the "Magic Villages" brand, it's evolution and the different projects generated around it. Materials and methods: The "Pueblos Mágicos" brand can be known throughout an ethnographic research. This research's information is issued by the federal government throughout different entities, specially the Ministry of Tourism (SECTUR). Results: Mexico has locations with attractive cultural diversity. It is important to make those locations known within Mexico and worldwide, to achieve a continuous growth of "Pueblos Mágicos" and that more and more states get recognition. Discussion: Since its inception, the project has undergone modifications, especially in the budget allocation due to changes in administration; however, it is necessary to make a comprehensive investment planning considering both the ecological balance and the economic growth of the inhabitants to achieve sustainable development. Then to publicize the relevant aspects that the accrediting bodies consider to grant the "Pueblos Mágicos" nomination. Conclusions: this article provides the opportunity to show the advantages and disadvantages of the "Pueblos Mágicos" brand in Latin America. It also helps other nations to apply similar projects so that their populations get benefits and be recognized as the "Culture is the only thing that can save people [...] it allows us to see misery and fight it, it allows us to see what needs to be changed and what should be left as is" (Periódico de Asambleas, 2017). Contribution/originality: The opinions shown in this article are based on the information from the main government secretariats involved in this project. The purpose of this re- 
Cómo citar este artículo /

Toreference this article:

Bolaños Ortega, R., Lizardi Rojo, V., \& Roldán Oropeza, N. A. (2021). Los Pueblos Mágicos y la relevancia de la educación cultural de sus habitantes para fomentar el turismo y el desarrollo local. Revista GEON (Gestión, Organizaciones Y Negocios), 8(2), e-442. https://doi. org/10.22579/23463910.442 search is to publicize the "Pueblos Mágicos" brand worldwide, especially in Latin America, which due to its history, architecture and culture can apply similar projects.

Keywords: Cultural nationalism; Cultural tourism; Economy; Educational environment; Growth and development.

Codes JEL: Z3 Tourist Economy; Z Other special topics

\section{Introducción}

Los edificios, paisajes, historias, recuerdos, encantos, y todas las singulares características que guarda celosamente cada rincón de las poblaciones de la república mexicana convierten a estas poblaciones en regiones especiales, mágicas... y al mismo tiempo merecedoras del conocimiento y reconocimiento nacional e internacional, constituidos por los recuerdos de sus visitantes, lo que contribuye a que sean postulantes del emblema que otorga la Secretaría de Turismo Federal. "Asentados en montañas, selvas, playas, valles y desiertos, los Pueblos Mágicos de México que componen esta lista son un botón de muestra de la gran riqueza natural, cultural y arquitectónica que tiene México" (Cachafeiro, México Desconocido, 2018).

A partir de 2001, se crea el programa regional Ilamado Pueblos Mágicos de México, cuyo fin es impulsar la actividad turística en ciertas localidades. Así, se busca "apoyar a estas poblaciones, mediante el ofrecimiento de productos turísticos diferenciados y diversificados, basados en la utiliza- ción y optimización de la oferta turística existente" (Shaadi-Rodríguez et al., 2017). Oficialmente, este nuevo concepto se reconoce como la "Localidad con Nombramiento, que es representada por su municipio, la cual a través del tiempo y ante la modernidad, ha conservado su patrimonio y manifiesta sus expresiones de forma excepcional" (Diario Oficial de la Federación, 2020). Como lo indica la Secretaría de Turismo (2020c), dependencia a cargo de este programa, estos territorios cuentan con íconos y leyendas, son pueblos que tienen historia, lugares que muestran identidad y hechos relevantes para la nación, ya que reflejan su personalidad en cada detalle, con la magia de sus encantos.

El 5 de junio de 2002, un año después de la creación del programa, se realizó un convenio general de colaboración en el cual participaron diferentes secretarías como la de Turismo, Desarrollo Social, Educación Pública, Trabajo y Previsión Social, Economía, Medio Ambiente y Recursos Naturales. De igual manera, participaron las comisiones Federal de Electricidad y la Nacional del Agua; el Fondo Nacional para el Fomento de las Artesanías, el 
Banco Nacional de Obras y Servicios, el Consejo Nacional para la Cultura y las Artes y el Instituto Nacional de Antropología e Historia. En ese entonces, se establecieron los fundamentos para la cooperación entre todas estas instituciones para ayudar a los Pueblos Mágicos en su desarrollo, gestación, apoyo, realización y evaluación de constante mejora. Es imperativa la colaboración de dichas instituciones y las dependencias del Gobierno para garantizar el proceso de continuidad del Programa Pueblos Mágicos (Diario Oficial de la Federación, 2020).

Los primeros pueblos en recibir el nombramiento fueron Huasca de Ocampo, en Hidalgo; Mexcaltitán, en Nayarit y Real de Catorce, en San Luis Potosí. En el último trimestre de 2015, el entonces secretario de turismo, Enrique de la Madrid Cordero, durante la 2. ${ }^{\text {a }}$ Feria de Pueblos Mágicos, cuya sede tuvo lugar en la capital de Puebla, dio a conocer que se agregaban 28 municipios al programa que, sumados a los 83 previamente incorporados, daban la totalidad de 111 Pueblos Mágicos a nivel nacional (Cachafeiro, 2020).

A partir del 1 de diciembre de 2020, oficialmente existen 132 Pueblos Mágicos en México (Secretaría de Turismo, 2020c). Cabe aclarar que un mismo estado puede tener varios de ellos; por ejemplo, Puebla cuenta con 10 ga- lardonados, todos con características particulares que los hacen mágicos.

En otro orden de ideas, los atractivos culturales o naturales apreciados en alguna localidad, su arquitectura y ofertas para que el visitante llegue y goce de esta población son parte de la oferta turística. ( Shaadi-Rodríguez et al., 2017). Estos lugares de viaje deben considerar productos de altura para que puedan hacer frente a la competencia internacional y no se enfoquen únicamente en satisfacer algunas necesidades atractivas para el turista. Además de ello, deben garantizar ese momento especial en la vivencia de su recorrido, incluyendo la trayectoria trazada. Dichas localidades también son un gran atractivo para el viajante de corte cultural que toma en cuenta los aspectos del pasado, contemporáneos y la forma de vida actual de un pueblo (Hernández-Glory, 2015).

En sus reglas de operación y estatutos para incorporarse y continuar en el proyecto, el Programa Pueblos Mágicos manifiesta la importancia de que la población cuente con un entorno cultural original, con raíces fuertes, pero, al mismo tiempo, con un conocimiento artístico y cultural universal (Hernández-Glory, 2015). Lo anterior se refleja en sus indicadores de evaluación de desempeño, los cuales se encuentran resumidos en la tabla 1.

Tabla 1. Indicadores evaluadores en el reglamento de operación de Pueblos Mágicos, mencionados en este documento (Hernández-Glory, 2015).

\begin{tabular}{l|l}
\multicolumn{1}{c|}{ Institucional y Gobierno } & Patrimonio y sustentabilidad \\
- Involucramiento con la sociedad & · Integridad y autenticidad del patrimonio \\
- Desarrollo cultural e histórico & \\
\hline
\end{tabular}


Las localidades que quieran conseguir o conservar esta distinción deben entrar en un proceso, que se publica en la convocatoria del sitio web de la Secretaría de Turismo (SECTUR [www. sectur.gob.mx]). Es menester ingresar una serie de documentos que deben ser validados por la Secretaría de Turismo, los cuales necesitan acreditar los siguientes puntos: un área administrativa oficial enfocada en atender el turismo de esa región, un directorio que incluya el nombre de los prestadores de servicios de este rubro, un inventario de atractivos turísticos y los recursos del lugar, principalmente aquellos inmuebles considerados - catalogados como monumentos históricos, ya sea a nivel federal o estatal, así como la información geográfica referente a conectividad y comunicación, y qué tan cerca están de los centros urbanos de distribución (kilometraje o tiempo para recorrerlos). Además, se debe considerar un plan o programa de desarrollo turístico municipal (Diario Oficial de la Federación, 2020). El Programa Pueblos Mágicos revalora las poblaciones que se encuentran en la imaginación colectiva de la sociedad, puesto que estas muestran alternativas originales y variadas a los turistas, ya sea a nivel nacional o internacional.

Todas las localidades que reciben el nombramiento de Pueblos Mágicos realizan obras para incrementar su atractivo, como pintar las fachadas de las casas, mejorar el alumbrado público y el drenaje y hacer mantenimiento a los monumentos patrimoniales. Estas obras son auspiciadas por los recursos de los Gobiernos Federales y Estatales. Además, Ios pueblos tienen acceso a la partida de obras públicas y seguridad. Así como reciben presupuesto por obtener tan galardonado nombramiento, deben cumplir con los objetivos específicos para conservar el distintivo. De no hacerlo, pueden ser sacados del programa, tal como estuvieron en peligro 14 de ellos en julio de 2018 (Valadez, 2018).

La LXIV Legislatura de la Cámara de Diputados (2019), en su primer año de ejercicio, estipuló los objetivos que debe cumplir un Pueblo Mágico para garantizar su permanencia en el programa:

- Apoyar a nuevos destinos para lograr su consolidación.

- Crear y renovar productos turísticos para diferentes áreas, aprovechando la singularidad de las localidades.

- Definir un plan turístico integral y variado para el público objetivo que se base principalmente en la atracción histórica y cultural.

- Atestiguar la calidad del servicio regional turístico.

- Hacer que el excursionista gaste en su viaje, generando ingresos para la región visitada.

- Propiciar la inversión del sector público y privado involucrados.

- Capacitar a los habitantes de las localidades.

- Hacer que el turismo apoye al desarrollo sustentable de estos lugares. 
- Renovar las regiones maduras existentes.

- Empoderar al turismo nacional.

Como se puede notar, conforme avanza el programa, se aplican criterios de mejora en el aspecto educativo, ya que los diputados consideraron la capacitación de los habitantes y planes turísticos integrales, basados en mayor medida en la atracción cultural e histórica.

Continuando con el aspecto cultural e histórico, la Ley General de Turismo (2009) se encarga de establecer los procesos que ayuden a conservar, mejorar, proteger, promover y aprovechar aquellos atractivos y recursos turísticos del país, sin olvidar la importancia de preservar el patrimonio nacional y cultural, logrando un equilibrio ecológico. También contribuye a crear y desarrollar nuevos atractivos apegados al marco jurídico actual (Shaadi-Rodríguez et al., 2017) Por lo que se observa, parte de la cultura ha evolucionado al considerar el aspecto de la sostenibilidad, puesto que en la primera década del siglo XXI la política turística de México se fue orientando "hacia la diversificación, la competitividad y la sostenibilidad, partiendo de una administración territorial del país que permita crear condiciones adecuadas para el turismo" (Shaadi-Rodríguez et al., 2017).

Considerando el sexenio actual, para el Gobierno de México, el turismo debe encaminarse a los principales indicadores propuestos en el Plan Nacional de Desarrollo 2019-2024, que consolidan a nuestro país como una potencia a nivel turístico "que logre el bienestar y el desarrollo justo entre individuos, comunidades y regiones, a través del aprovechamiento sostenible del patrimonio natural y cultural" (Diario Oficial de la Federación, 2020).

Aun cuando la cultura, especialmente la ecológica, forma parte del desarrollo sostenible, no hay que olvidar la indispensabilidad del aspecto económico. Hablando de este factor, es responsabilidad de la Secretaría de Turismo a nivel federal el mantener el concepto de Pueblos Mágicos como una marca distintiva del turismo mexicano, aumentar su valor como oferta turística nacional y aprovechar su potencial, además de intentar generar una mayor derrama en su economía para coadyuvar en el bienestar social, preservando la identidad de cada localidad (Diario Oficial de la Federación, 2020). El programa es un gran impulso para la industria. Según diversos funcionarios turísticos, esta es una de las principales razones para que la marca se haya convertido en una de las más exitosas en materia turística (Martínez, 2018). Ejemplo de ello es que, en el período correspondiente a 2010-2015, se notó una disminución del 2,1\% de la población nacional con pobreza y del 3,4\% en la pobreza extrema. En el caso de los habitantes de los Pueblos Mágicos, esta disminución se notó aún más, ya que fue de 3,5 y 4,8 puntos porcentuales, respectivamente (Secretaría de Turismo, 2020c).

Además de los beneficios mencionados, en esta investigación se detectó que en el año 2017 el Programa Pue- 
blos Mágicos movilizó a 4,6 millones de excursionistas nacionales e internacionales, lo que equivale al 11,5\% del total de visitantes en el territorio mexicano (Martínez, 2018).

Por otro lado, de acuerdo con otros autores más críticos, aunque el programa genera beneficios económicos, sociales y culturales, y disminuye los indicadores de pobreza, esto no refleja un gran impacto porque la media nacional es superior, bajo el argumento de que "la proporción de población en pobreza registrada en 2015 es del 43,9\% como valor nacional contrastando con el 50,4\% en los municipios con Pueblos Mágicos, y en pobreza extrema del 7,9\% a nivel nacional contra el 8,7\% en los 123 municipios" (Gobierno de México, 2020).

Para dar seguimiento a este tipo de análisis e investigaciones, se deben fortalecer y actualizar las bases de datos con información certera para enriquecer los sistemas estadísticos y geográficos. De esta manera, surgirá un mayor número de propuestas para impulsar adecuadamente al desarrollo turístico. Por citar un ejemplo, "al cierre de 2018, solo el 27\% de las localidades con esta denominación cuentan con información estadística parcial de la actividad turística, lo que imposibilita que a más de 17 años de su operación se dimensione el impacto real del turismo en dichos destinos" ( Secretaría de Turismo, 2020b).

Finalmente y sin lugar a dudas, la marca Pueblos Mágicos es un tema complicado porque la información que se tiene está basada en los decretos emitidos por el Gobierno Federal con ayuda de la Secretaría de Turismo y otras dependencias. Algunos beneficios se ven a simple vista por las mejoras arquitectónicas que sufre el inmueble de cada localidad, pero, de acuerdo a esta investigación de tipo etnográfica y el análisis de reflexión interpretativa, hay factores que son difíciles de comprobar, por ejemplo, la aparente o nula información de estatutos que indiquen qué se puede o no modificar en cuanto a la estructura del inmueble para no perder su originalidad y, si existe, cuál es la instancia encargada de regular que se respete.

"El turismo puede fomentar la comprensión internacional, la paz y la buena voluntad, pero en el largo plazo, el bienestar económico de los residentes debe ser una preocupación central de la noción de competitividad del destino" (Shaadi-Rodríguez et al., 2017).

\section{Reflexión}

Tomando en consideración el tema de la educación relativa al desarrollo sostenible, cabe mencionar que las empresas privadas unen los objetivos del mercado con los de las iniciativas sociales, teniendo en cuenta las siguientes variables:

1. Debe existir uniformidad entre el portafolio de recursos y sus activos.

2. Las estrategias deben ser diferentes a las de la competencia.

3. Aprovechar el conocimiento del consumidor como ventaja de renombre de la marca. 
4. Este valor creado debe beneficiar a la empresa de manera directa (Ninco-Hernández \& Duque-Orozco, 2017).

Esto se puede apreciar gráficamente en la figura 1:

Figura 1. Relación de valor creado. Tomada de Ninco-Hernández y Duque-Orozco (2017).

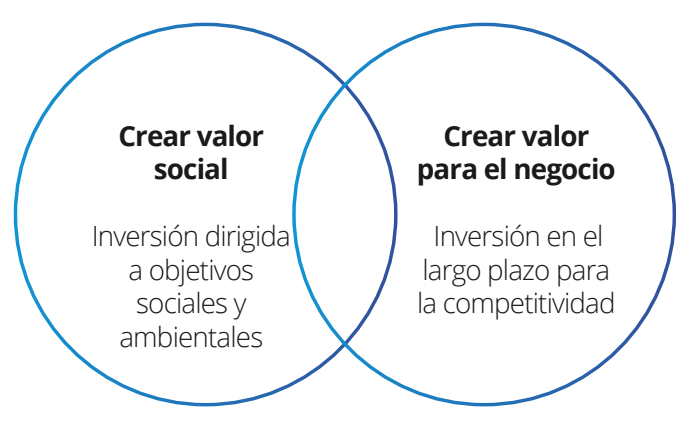

Ninco-Hernández y Duque-Orozco (2017) también aseguran que es importante generar prácticas socialmente responsables que les den ventajas competitivas, sin olvidar la retribución económica. Para lograrlo es posible integrar el análisis de la cadena de valor dentro de los enfoques propuestos para direccionar las actividades realizadas con objetivos rentables y en búsqueda de innovación. Parte del sector del turismo nacional visita los Pueblos Mágicos para apoyar la economía local, entre otros muchos factores.

De esta manera, es posible "anclar la cultura en todas las políticas de desarrollo...", incluyendo la educación y el turismo, "sostener el desarrollo del sector cultural mediante industrias creativas: así, a la vez que contribuye a la reducción de la pobreza, la cultura constituye un instrumento de cohesión social" (Naciones Unidas, 2021).

Para la captación de turismo educativo, por citar un ejemplo, los exgobernadores de Puebla, Antonio Gali Fayad y Rafael Moreno Valle, en sus respectivos momentos, apoyaron la inversión en materia de atractivos deportivos, culturales y turísticos. Lo anterior favoreció la inscripción del estado en la Red de Ciudades Creativas de la Organización de las Naciones Unidas para la Educación, la Ciencia y la Cultura. Tanto fue el interés por reflejar su pertenencia, que decidieron darle el nombre de Capital del Diseño a su cuidad principal. En ese orden de ideas, el 24 de marzo de 2017, se le otorgó a Puebla el reconocimiento de la Denominación de Origen del Mezcal, consolidándola como el segundo lugar de los estados del país con el mayor número de localidades en obtener esta legitimación (Lizardi et al., 2017).

Dando este enfoque de valor al Programa Pueblos Mágicos, de acuerdo con el Censo de Población y Vivienda 2014, analizado por SECTUR en 2016, "el total de unidades económicas que operaron en los 32 Pueblos Mágicos aquí considerados generaron 117,972 ocupaciones, equivalente al 4,3\% del total turístico por Pueblo Mágico" (Secretaría de Turismo, 2016). A nivel del turismo, los sectores económicos que producen el mayor número de ocupación son, por un lado, alimentos y bebidas y, por el otro lado, alojamiento temporal. En cuanto a los negocios, a menudeo se contaba "con un total de 49.273 y 49.030 personas ocupadas en 2013, respectivamente, 
equivalentes al $41,8 \%$ y $41,5 \%$ del total de puestos de trabajo en los Pueblos Mágicos" (Secretaría de Turismo, 2016). Sin embargo, de acuerdo con el director de Gestión de Destinos de SECTUR en 2018, José Ángel Díaz Rebolledo, se debe garantizar la capacidad de alojamiento de algunos Pueblos Mágicos, ya que en temporadas vacacionales se tienen problemas de capacidad (Martínez, 2018).

En la generación de puestos de trabajo, los referentes a alimentos y bebidas contribuyeron con el 33,8\%, seguidos de las ramas de comercio al por menor con el 12,3\%, productos textiles con el 11,2\%, bisutería, calzado y accesorios de vestir, divertimento y demás artículos personales con el 10,3\%. En cuanto a fotografía y videograbaciones, se observó un total de 529 personas ocupadas, que equivale al 0,45\% de la actividad económica turística en Pueblos Mágicos ( Secretaría de Turismo, 2016).

Es importante destacar que de los 32 Pueblos Mágicos censados, 12 de ellos generaron un poco más de la mitad del total de puestos de trabajo, es decir, el 51,6\%. Estos son: Lagos de Moreno, Dolores Hidalgo, Coatepec, Valle de Bravo, Metepec, San Cristóbal de las Casas, Comitán de Domínguez, Taxco, Cholula, Pátzcuaro, Valladolid y Tecate.

La inversión destinada al programa varía de acuerdo con el monto que asigne la administración de turno, y desde su inicio ha sufrido tanto altas como bajas. En el Presupuesto de Egresos de la Federación, tomado en cuenta en el Ejercicio Fiscal 2016, se destinaron
1571,71 millones de pesos al Programa para el Desarrollo Regional Turístico Sustentable y Pueblos Mágicos (PRODERMÁGICO). Para 2017, solo se asignaron 568.918.886 pesos y para 2018, la cantidad fue de 585.986.452 pesos (LXIV Legislatura, 2019).

Debido al gran impacto que el nombramiento de este programa representa para los municipios y localidades, en octubre de 2018 SECTUR presentó una Proposición con Punto de Acuerdo en la cual solicitaron que en el Plan Nacional de Desarrollo 2019-2024 se marcara como estrategia aumentar la inversión al turismo y dirigirla especialmente al Programa Pueblos Mágicos (LXIV Legislatura, 2019). Además, exhortaron a la Cámara de Diputados a que considerara asignar un presupuesto igual o mayor que el del 2016, mencionado anteriormente (LXIV Legislatura, 2019).

Otro punto de vista a considerar es el hecho de que parte del monto asignado se ocupa para realizar transformaciones que reciben los Pueblos Mágicos, tanto para obtener el nombramiento como para mantenerlo. Podría pensarse que estas transformaciones son un beneficio para la localidad; sin embargo, existen opiniones que sugieren lo contrario, ya que se piensa que el patrimonio se considera un artículo de consumo, pues los edificios, habitantes, espacios naturales y tradicionales se deben transformar en elementos atractivos para cautivar a los consumidores turísticos. "Para lograr esa feliz "confirmación", es necesario transformar el producto turístico" (Rojo-Quintero \& 
Llanes-Gutiérrez, 2009). Los productos culturales empiezan a volverse homogéneos, se estandarizan y, además, se crea una dependencia con el mercado y los grandes emporios de mercadotecnia, publicidad y otros negocios. "Dichos "productos" no se cuestionan: simplemente se asumen" (Asamblea Popular de Coslada 15M, 2017).

Un ejemplo de ello ocurre en Tequila Jalisco, donde las construcciones generalmente se adornan con estilo barroco, "tomado como sinónimo de historicidad, de lo auténtico, lo nacional" (Rojo-Quintero \& Llanes-Gutiérrez, 2009) y, en la realidad, nunca existieron elementos de este estilo en esos espacios. Igualmente sucede con los elementos intangibles, puesto que "algunas historias son inventadas o reinventadas, las danzas y vestuarios regionales son cambiados o remodelados y todo con el afán de adaptarlo para el consumo de una masa cada vez más globalizada".

\section{Conclusión}

Ser un Pueblo Mágico es, sin lugar a duda, una gran distinción. Una de las razones de mayor envergadura es que pertenecer al Programa significa entrar a un mundo promovido a nivel internacional. Las remodelaciones e inversiones que se reciben por parte de los Gobiernos Estatal y Federal podrían beneficiar a la localidad en general, sin mencionar el flujo de visitantes que ayudan a movilizar la economía y a generar empleos. Para asegurar lo anterior, es importante supervisar que los beneficios se refle- jen directamente en los ciudadanos de la región y no únicamente en unos cuantos empresarios.

Es imperioso acrecentar la promoción y divulgación de los Pueblos Mágicos para aumentar la captación de turismo extranjero. Esto a consecuencia de que, independientemente de haber comprobado que las playas son las que tienen el mayor número de visitantes, la condición de ser mágicos es un factor relevante que respalda la idea de que sería enriquecedor visitar sitios culturalmente alternos. Para fomentar la afluencia del turismo que prefiere enriquecer su nivel cultural, es necesario que los mismos habitantes sean conscientes tanto de su historia como de los usos y costumbres de su propia localidad. Ellos deben ser congruentes con lo que promueven y estar orgullosos de su región para transmitirlo a los visitantes, pues esto coadyuva al incremento de la educación cultural del pueblo mexicano.

Se ha comprobado en esta reflexión que cada vez que se lleva a cabo un cambio de Gobierno, por cuestiones políticas, se reducen o amplían los recursos asignados a este proyecto turístico, lo cual lo beneficia o perjudica según sea el caso. Esta comprobación sustenta la idea de que, independientemente de la administración que se encuentre en el Gobierno, lo apropiado es mantener los apoyos sin que se perturbe la cantidad presupuestal que reciben los Pueblos Mágicos a raíz de este nombramiento, ya que su permanencia depende del presupuesto asignado y sin este monto se ven mermados los objetivos. Aunado 
a lo anterior, es indispensable auditar y verificar que las estrategias que se van implementando para enriquecer el programa se ejecuten de manera adecuada y cumplan con los objetivos integrales que fomentan el turismo y minimizan la pobreza de nuestro país.

Dada esta situación que se da con cada nueva administración, es importante analizar las estrategias que el Gobierno actual promueve para anteponerse a los cambios, adaptarse a ellos y lograr el mayor beneficio. Una de las más recientes surgió a partir de 2020, al decretarse el 5 de octubre como el Día Nacional de los Pueblos Mágicos. (Diario Oficial de la Federación, octubre 2020). Es menester de la Secretaría de Turismo definir los mecanismos adecuados para implementar el decreto antes mencionado, aprovechando los recursos programados y asignados actualmente para cada dependencia. La declaración de Día Nacional de los Pueblos Mágicos puede ser benéfica para generar la identidad de lo que significa esta insignia, ya que, con el correr de los años, un mayor número de mexicanos se sentirá identificado con el programa y ello despertará su curiosidad por conocer al menos uno de los 132 pueblos que actualmente existen en el país. Lo anterior está comprobado con base en otros decretos de días nacionales.

Otra de las recientes estrategias que ya se han llevado a cabo y están señaladas en el Programa Sectorial de Turismo 2020-2024, por su actual secretario Miguel Tomás Torruco Marqués, es que se deben tomar acciones que partan de cuatro principales objetivos: garantizar el respeto a los derechos humanos en turismo a nivel nacional, favorecer el equilibrio en el desarrollo de los destinos turísticos mexicanos, aumentar la diversidad del mercado turístico nacional y extranjero, y fortalecer el turismo sostenible en el país. Es importante ver que dichas acciones se lleven a cabo para que no se queden en el tintero. Un ejemplo de ello es la construcción de nuevos medios que favorezcan las vías de comunicación y el acceso a lugares que hasta ahora son considerados de difícil llegada.

El Ilamado Tren Maya "aprovechará los recursos turísticos mediante circuitos que abarcan playas, zonas arqueológicas, museos, Pueblos Mágicos y Ciudades Patrimonio Mundial de la Humanidad" (Secretaría de Turismo, 2020b). A pesar de la polémica generada en torno a su creación, si se concluye esta estrategia, el beneficio a mediano y largo plazo podría ser substancial para los Pueblos Mágicos aledaños a su ruta, tanto en la promoción como en el acceso de la llegada a las estaciones destino. Se considera así, bajo el sustento del tren Chepe, el cual recorre paisajes espectaculares, atravesando bosques, ríos y montañas, cuyo trayecto va de los Mochis hasta Creel, con cinco estaciones turísticas que benefician al Pueblo Mágico de El Fuerte y a la comunidad indígena más importante de Barrancas de Cobre, pueblo también reconocido con este nombramiento. Caso contrario sería el del llamado tren turístico Puebla-Cholula, construido durante la administración del difunto gobernador Rafael Moreno Valle, cuyo destino turístico es el Pueblo Mágico 
de Cholula y que, de acuerdo con la nota periodística del Sol de Puebla de 2019 (Cancino, 2019), se ha considerado como un fracaso al tener pocos pasajeros y dos terminales intermedias sin funcionamiento. Dada esta dualidad, quedará para futuras investigaciones comprobar la asertividad de la nueva inversión.

Otro aspecto para considerar es que la pandemia de COVID-19 provocó la disminución de las llegadas de turistas internacionales en un 22\% a inicios de 2020, según la Organización Mundial del Turismo, quien también afirma que lo antes dicho podría declinar aún más (entre el 60\% y el 80\%) comparado con 2019. Como se puede notar, se "pone en riesgo el medio de sustento de millones de personas y amenaza con deshacer el camino andado hacia los Objetivos de Desarrollo Sostenible" (UNESCO, 2020). Derivado de la actual problemática presentada, algunos estados han seguido haciendo promoción de sus localidades turísticas y han implementado nuevas medidas sanitarias con el fin de sobrellevar la situación. Así mismo, algunos museos han recurrido a innovaciones, mudándose a medios virtuales para la difusión de sus recintos. Cabe mencionar que aquí únicamente se analiza el impacto a nivel turismo, aunque es tarea de otros autores profundizar en los factores intrínsecos de este tema.

Otra de las medidas que se han realizado para solventar la problemática que ha traído la pandemia es la que se llevó a cabo en el seminario Patrimonio y Turismo Cultural, dentro del
Movimiento Aguascalientes, Recuperación y Resiliencia (UNESCO, 2021a; 2021b), donde se abordó la necesidad de hacer partícipe a la comunidad en preservar su patrimonio histórico. De igual manera, en el sector educativo, enfatizar la apreciación del valor de dicho patrimonio por parte de infantes, adolescentes, jóvenes y familias. Para lograr estas acciones, Gloria López Morales (escritora, periodista y diplomática mexicana) propuso diseñar, de manera conjunta con las redes formales educativas, un proyecto enfocado en la apreciación cultural infantil. Para respaldar la idea de la escritora, Jordi Tresseras (director de IBERTUR) señaló que es una parte importante el que la gente conozca todos los aspectos culturales y turísticos del país, porque el "turismo de casa" podría ser un punto estratégico para favorecer a este sector en nuestra nación (UNESCO, 2020).

Por último, como ya se ha mencionado con antelación, esta investigación basa su análisis mayormente en fuentes de información gubernamentales, la cuales podrían ser subjetivas, ya que cada administración justifica su acción como plausible $y$, en ocasiones, minimiza los quehaceres de las autoridades previas a ellos, razón por la cual también se buscaron críticas alternas para poder enriquecer las opiniones dadas en este documento. Aun así, es importante considerar la investigación de campo para generar nuevas conclusiones. En este aspecto, las Universidades Tecnológicas actualmente realizan estudios de campo en diferentes estados de la república, cuyo objetivo es conocer el impacto económico 
y social que representa el distintivo de Pueblo Mágico desde el punto de vista de los empresarios y ciudadanos.

\section{Información Complementaria}

Agradecimientos: agradecemos a la Revista GEON por la oportunidad de publicar este artículo que contribuye a la perenne lucha por conservar el Programa Pueblos Mágicos e incrementar las localidades que obtengan el distintivo sobre el que se ha reflexionado aquí.

Contribuciones de autoría: para la realización de este artículo se contó con la participación de la maestra Norma Angélica Roldán Oropeza en la recopilación e investigación de la información. La licenciada Rosalba Bolaños Ortega y la maestra Verónica Lizardi Rojo quedaron a cargo de la selección de la información, el análisis, la reflexión y la determinación de las conclusiones, así como de la estructuración, traducción y redacción del documento.

El enlace y seguimiento del cumplimiento de los requerimientos para la aprobación y publicación del presente estuvieron a cargo de las dos últimas docentes mencionadas.

\section{Conflictos de interés: no existe} ningún conflicto de interés que afecte la objetividad del manuscrito, ya que las tres autoras investigadoras, a pesar de ser nativas de este país, laboran en la Universidad Tecnológica de Puebla, organismo descentralizado, es decir, el subsidio que recibe es de ambos Gobiernos, Federal y Estatal. Es relevante recalcar que en dicha institución prestan sus servicios profesionales como profesoras de tiempo completo y pertenecen a un Cuerpo Académico. Todas las opiniones aquí plasmadas están basadas en su análisis y perspectivas experienciales; además de ello, se referenciaron los aspectos positivos y negativos de la marca Pueblos Mágicos, buscando evitar la subjetividad.

Financiamiento: no se contó con el financiamiento de ninguna institución ni fondo para la elaboración de este artículo, ya que todo lo presentado en él está basado en información publicada por organismos oficiales del Gobierno de la República de México. Cabe mencionar que si la publicación genera un costo, este será cubierto por la Universidad Tecnológica de Puebla.

\section{Referencias}

Asamblea Popular de Coslada 15M. (2017, 26 de junio). Cultura del pueb/o. Madrid 15M. Periódico de Asambleas. https://bit.ly/3zUiUx3

Cámara de Diputados del H. Congreso de la Unión. (2009, 31 de julio). Ley General de Turismo. https://bit.ly/3if2BoW

Cancino, B. (2019, 22 de febrero). Fracasa costoso tren turístico Puebla-Cholula. El Sol de Puebla. https://bit.ly/3ATM7tm

Diario Oficial de la Federación (2020, 10 de marzo). Acuerdo por el que se establecen los criterios generales para el Nombramiento de Pueblos Mágicos. https://bit.ly/3zNWKNg

Diario Oficial de la Federación. (2020, 5 de octubre). Decreto por el que se declara el 5 de octubre de cada año como el "Día Nacional de los Pueblos Mágicos". https://bit.ly/3EXpGpH 
Entrepreneur. (2020, 11 de diciembre). ¿Qué se necesita para convertirse en un Pueblo Mágico? https://www.entrepreneur.com/article/361354

Gobierno de México. (2020). Estrategia nacional de Pueblos Mágicos. Anexos. Diagnóstico socioeconómico de los Pueblos Mágicos. https://bit.ly/3py4kdm

Hernández-Glory R. A. (2015, 15 al 17 de octubre). Modelo de Formación en Turismo Cultural mediante el uso de tecnología, dirigido a los habitantes del Mágico Palizada, Campeche [ponencia]. 2. ${ }^{\circ}$ Encuentro Nacional de Gestión Cultural, San Pedro Tlaquepaque, Jalisco, México. https://bit.ly/3m08zuA

Lizardi-Rojo, V., Bolaños-Ortega, R., Roldán-Oropeza, N. A. \& Titla-Flores, M. (2017). El impacto de las TIC para el turismo educativo en el estado de Puebla. Ecorfan.Org. https://bit.ly/3CRbpcn

Martínez, A. (2018, 12 de octubre). ¿Qué beneficio tiene ser un pueblo mágico? Grupo en Concreto. https://bit. ly/2Zh1tuF

México Desconocido. (2018, 18 de abril). Pueblos Mágicos de México, lista completa de los 132. https://bit.ly/3m9ljOr

Movimiento Global ResiliArt. (2021).

Naciones Unidas. (2021, 21 de mayo). Día Mundial de la Diversidad Cultural para el Diálogo y el Desarrollo, 21 de mayo. https://bit.ly/3zNzRJF

Ninco Hernández, F. A., \& Duque Orozco, Y. V. (2017). Enfoques de la responsabilidad social empresarial innovadora: alternativas para las organizaciones de hoy. Revista GEON (Gestión, Organizaciones Y Negocios), 4(1), 162-175. https://doi.org/10.22579/23463910.52

Rojo-Quintero, S., \& Llanes-Gutiérrez, R. A. (2009). Patrimonio y turismo: el caso del Programa Pueblos Mágicos.
Topofilia Revista de Arquitectura, Urbanismo y Ciencias Sociales, 1(3),1-15. http://148.228.173.140/topofiliaNew/ assets/coloquio09rojo-llanes.pdf

Secretaría de Turismo (2016). Estadística Turística Derivada de los Censos Económicos 2014. Pueblos Mágicos. https:// bit.ly/3zJJk4l

Secretaría de Turismo (2020a). Estrategia Nacional de Pueblos Mágicos. Anexos. Diagnóstico socioeconómico de los Pueblos Mágicos. https://bit.ly/39HGId8

Secretaría de Turismo (2020b). Programa Sectorial de Turismo 2020-2024. https://bit.ly/3ul82ay

Secretaría de Turismo (2020c, 1 de diciembre). Pueblos Mágicos de México. https://bit.ly/3zJtBCR

Senado de la República de México. LXIV Legislatura, Primer Año de Ejercicio. (2019, 19 de marzo). Proposición con punto de acuerdo. Por el cual el Senado de la República exhorta respetuosamente al Ejecutivo Federal, para que, por medio de la Secretaría de Hacienda y Crédito Público, lleve a cabo las adecuaciones presupuestarias necesarias, a fin de en el ejercicio fiscal 2019, se reasignen recursos económicos al Programa de Desarrollo Regional Turístico Sustentable y Pueblos Mágicos, apoyando directamente a los 121 destinos turísticos que cuentan con nombramiento de Pueblo Mágico vigente. https://bit.ly/3ujzUM8

Shaadi-Rodríguez, R. M. A., Pulido-Fernández, J. I. \& Rodríguez Herrera, I. M. (2017). El producto turístico en los Pueblos Mágicos de México. Un análisis crítico de sus componentes. Revista de Estudios Regionales, (108),125-163. [fecha de Consulta 28 de Septiembre de 2021]. ISSN: 0213-7585. Disponible en: https://www.redalyc.org/articulo. oa?id=75551422005 
UNESCO. (2020, 26 de junio). Educación y corresponsabilidad, las claves para recuperar la actividad cultural y turística en México. https://bit. ly/2ZzOvaZ

UNESCO. (2021a). Cultura y desarrollo. https://bit.ly/2XEb8d]
UNESCO. (2021b). Movimiento Global Resiliart en México. https://bit. ly/3pMnzA7

Valadez, R. (2018, 23 de julio). Hay 14 Pueblos Mágicos en riesgo de salir del programa. Grupo Milenio. https:// bit.ly/3ASJnfT 